\title{
Castor oil as a potential renewable resource for the production of functional materials
}

\author{
Egid B. Mubofu*
}

\begin{abstract}
Castor oil is increasingly becoming an important bio-based raw material for industrial applications. The oil is nonedible and can be extracted from castor seeds from the castor plant belonging to the family Euphorbiaceae. The oil is a mixture of saturated and unsaturated fatty acid esters linked to a glycerol. The presence of hydroxyl group, a double bond, carboxylic group and a long chain hydrocarbon in ricinoleic acid (a major component of the oil), offer several possibilities of transforming it into variety of materials. The oil is thus a potential alternative to petroleum-based starting chemicals for the production of materials with variety of properties. Despite this huge potential, very little has recently been reviewed on the use of castor oil as a bio-resource in the production of functional materials. This review therefore highlights the potential of castor oil in the production of these diverse materials with their projected global market potential. The review gives the background information of castor oil and its geographical availability, the properties and its uses as bio-based resource for synthesis of various materials. The review further highlights on the use of castor oil or ricinoleic acid as a green capping agent in the synthesis of nanomaterials.
\end{abstract}

Keywords: Castor oil, Ricinoleic acid, Derivatization of castor oil, Hydrogenated castor oil (HCO), Capping agent, Nanomaterials

\section{Background}

Castor plant (Ricinus communis) is from the family Euphorbiaceae and grows wild in varied climatic conditions. The plant produces castor seeds that contain up to $50 \%$ castor oil by weight. The oil can easily be extracted from castor seeds and find its use in a multitude of sectors such as medicine, chemicals industry and in other technologies [1]. The demand for castor oil and its products in the world market has been on the steady increase [2] partly due to their renewable nature, non-competition with food, biodegradability, low costs, and eco-friendliness. It is now estimated [2] that the oil has over 700 industrial uses and the uses keeps on increasing.

The chemistry of castor oil is mainly centered on ricinoleic acid due to its high content in the oil and the presence of the three functional groups in the acid. The three

\footnotetext{
*Correspondence: ebmubofu@gmail.com; ebmubofu@udsm.ac.tz Chemistry Department, University of Dares Salaam, P.O. Box 35061, Dar Es Salaam, Tanzania
}

functionalities are crucial towards the versatility of the oil for the production of variety of castor oil based products. The carboxylic group for instance, can lead to a wide range of esterification products while the single point of unsaturation can be altered by hydrogenation, epoxidation or vulcanization. On the other hand, the hydroxyl functional group at carbon-12, can be acetylated, alkoxylated or removed by dehydration to increase the unsaturation of the oil.

The reactions of castor oil are becoming of high industrial importance. This paper reviews on the geographical distribution of castor plants and the world production of castor seeds and castor oil. Furthermore, some important reactions on converting castor oil into useful products is discussed. The reactions discussed include hydrogenation, pyrolysis, caustic fusion, dehydration, transesterification, sulphonation, and polymerization. The use of castor oil and ricinoleic acid as green capping agent in the synthesis of nanomaterials is highlighted. 


\section{Review}

\section{Geographical distribution of castor plant and the world production of castor seeds}

Castor is a non-edible oil crop (Fig. 1) which grows throughout the tropics, subtropics and is well adapted in some temperate climates [3]. Castor plant (Ricinus Communis) is perennial and grow between 10 and $12 \mathrm{~m}$ in tropical climates while in temperate climates it is an annual plant with common heights of 1-3 m [3]. For maximum oil yield, the plant needs an environment with a temperature between 293 and $303 \mathrm{~K}$, low humidity throughout the growing season, and soils that are deep, moderately fertile, slightly acidic, well drained, and sandy loams $[3,4]$.

The world castor seed production has increased from 1.055 million tons in 2003 to 1.440 million tons in 2013 with India being the leading producer and accounts for over $75 \%$ of the total production followed by China and Brazil each accounting for 12.5 and $5.5 \%$ respectively (Fig. 2) [4]. This increase of about $36 \%$ production in a decade is linked to castor oil's easy availability, low cost, non-food competition, high boiling point, high viscosity and other environmental considerations. Combination of these reasons makes castor oil to have a huge potential as a green bio-based chemical resource. At present, the major castor markets are the USA, China, Russia, Japan and the European community countries [5].

India being the largest producer of castor seeds, it also heavily dominates in castor oil production worldwide. Overall, there has been a world-wide increase in castor oil production [5] from 0.425 million tonnes in 2003 to 0.681 million tonnes in 2012 which is about $40 \%$ increase in almost a decade (Fig. 3).

The world-wide increase in castor oil production witnessed in the past decade is a clear testimony of the wide range of applications of castor oil and its derivatives in various sectors. The oil is presently used in sectors such as agriculture, food, textile, paper, plastic, rubber, cosmetics, perfumeries, electronics, pharmaceuticals, paints, inks, additives, lubricants and biofuels $[1,8]$. The advances made during the last decade in using plant oils and basic oleochemicals in the synthesis and production of diverse products including polymers is remarkable [9, 10]. In the advances, castor oil is among the most versatile plant oil owing to its unique chemical structure that makes it useful in a wide range of industries. It is among the most sought after plant oil mainly due to its rich properties and variety of end-uses.

\section{Castor oil and derivatives global market}

Owing to its rich properties and variety of end-uses, together with increased interests in biopolymer and biofuels industries, the potential for castor oil to play a much larger role in the world economy has increased dramatically in recent years. For instance, trend shows that castor oil prices steadily rose from $\$ 946$ per tonne in 2002-2003 to $\$ 2390$ in 2010-2011 [5]. The contribution of castor oil on the world economy is expected to continue increasing and it has been predicted that the global castor oil and derivatives market will reach USD 1.81 billion by 2020 [6]. The increased interest of substitution of conventional fuel by bio fuels, volatile crude oil prices, higher demand from Europe, China and the US, and growth of key enduse industries including cosmetics and lubricants are expected to drive the global castor oil and derivatives market. On the other hand, threat from other vegetable oils in terms of price and application, and high dependency on seasonality may hinder the market growth. Some major companies operating in the castor oil and derivatives global market are: Thai Castor Oil Industries Co.
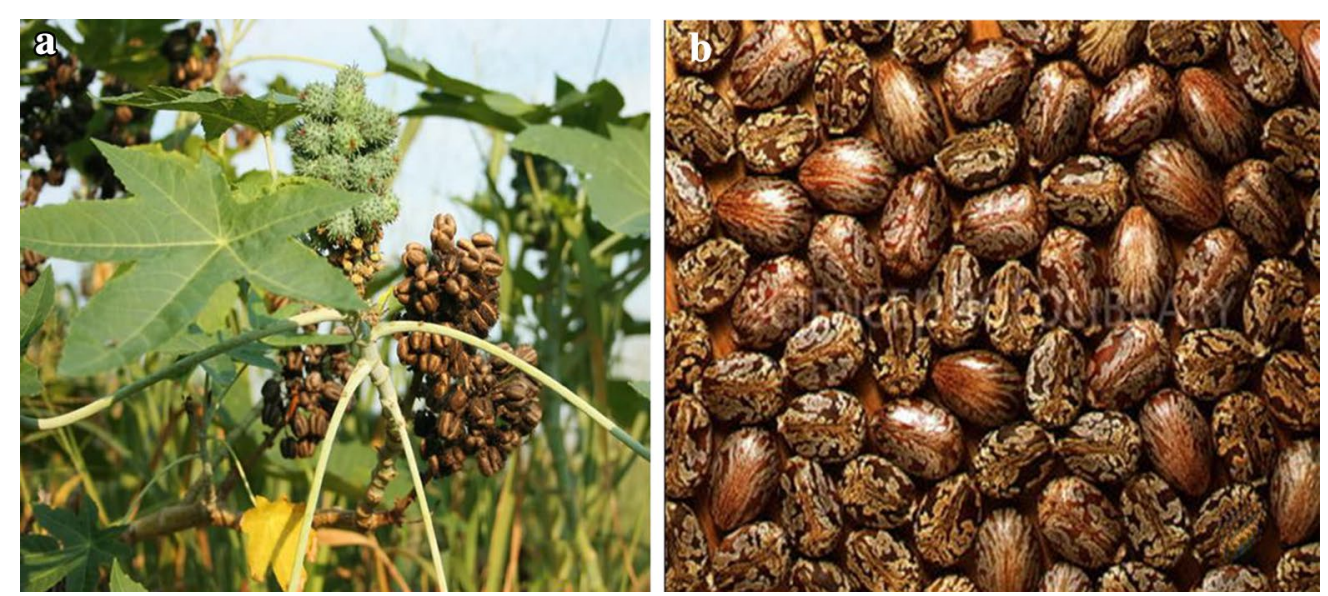

Fig. 1 Castor plant (a) and castor seeds (b) 


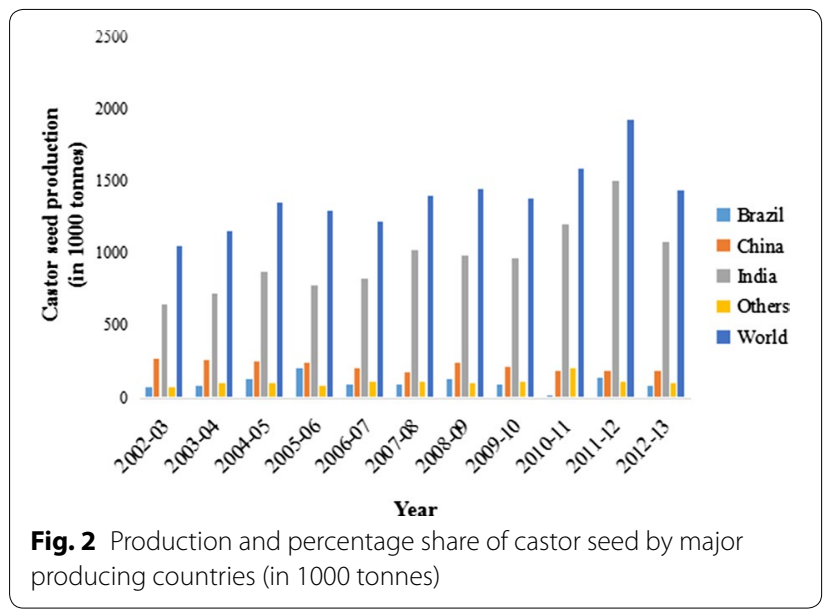

Ltd., Jayant Agro Organics, Hokoku Corporation, ITOH Oil Chemicals Co. Ltd., Gokul Overseas, Bom Brazil, Liaoyang Huaxing Chemical Co., Ltd., and Kanak Castor Products Pvt. Ltd [7].

\section{Extraction, composition and properties of castor oil}

Castor oil can be extracted from castor seeds by solvent extraction, mechanical pressing or a combination of both [8]. Mechanical pressing is disadvantageous as it can only extract about $45 \%$ of the oil. This means that the rest of the oil in the cake must again be extracted by a solvent and therefore causing double work, increase in extraction expenses and thus the process become environmentally unfriendly. On average, castor seeds contain between 45 and $55 \%$ oil by weight depending on the varieties, geographical location and the method of extraction [1]. Like other vegetable oils, castor oil exists as a mixture of saturated and unsaturated fatty acids attached to a glycerol $[15,16]$. In the mixture of castor oils fatty acids, ricinoleic acid accounts for about $90 \%$ of the mixture with other components in small proportions of not more than $5 \%$ (Fig. 4).

Castor oil is extracted colourless to very pale yellow viscous liquid with a distinct taste, mild odour and it boils at $586 \mathrm{~K}$ [10]. The hydroxyl group in ricinoleic acid (Fig. 4a) account for the unique properties of castor oil. For instance, the oil has relatively high viscosity and specific gravity; it is soluble in alcohols in any proportion and has limited solubility in aliphatic petroleum solvents [11]. In addition, the polar hydroxyl group in castor oil makes it compatible with plasticizers of a wide variety of natural and synthetic resins, waxes, polymers and elastomers [12]. Notable changes on the properties of the castor oil can also be due to several factors such as the method of extraction, seed varieties, weather conditions and soil type. For instance, cold-pressed castor oils have low acid value, low iodine value and a slightly higher saponification value than solvent-extracted oil [1]. It has further been observed that castor seeds from different climatic conditions produce castor oils of different composition and physical-chemical properties [14, 15, 17]. Malaysian castor seeds for instance, contain total lipids (castor oil) reaching up to $43.3 \%$ per dry weight and a saponification value of $182.96 \mathrm{mg} \mathrm{KOH} / \mathrm{g}$ [14] while for the Nigerian castor seeds, the total lipids (castor oil) is $48 \%$ per dry weight with a saponification value of $178.00 \mathrm{mg} \mathrm{KOH} / \mathrm{g}$ [15].

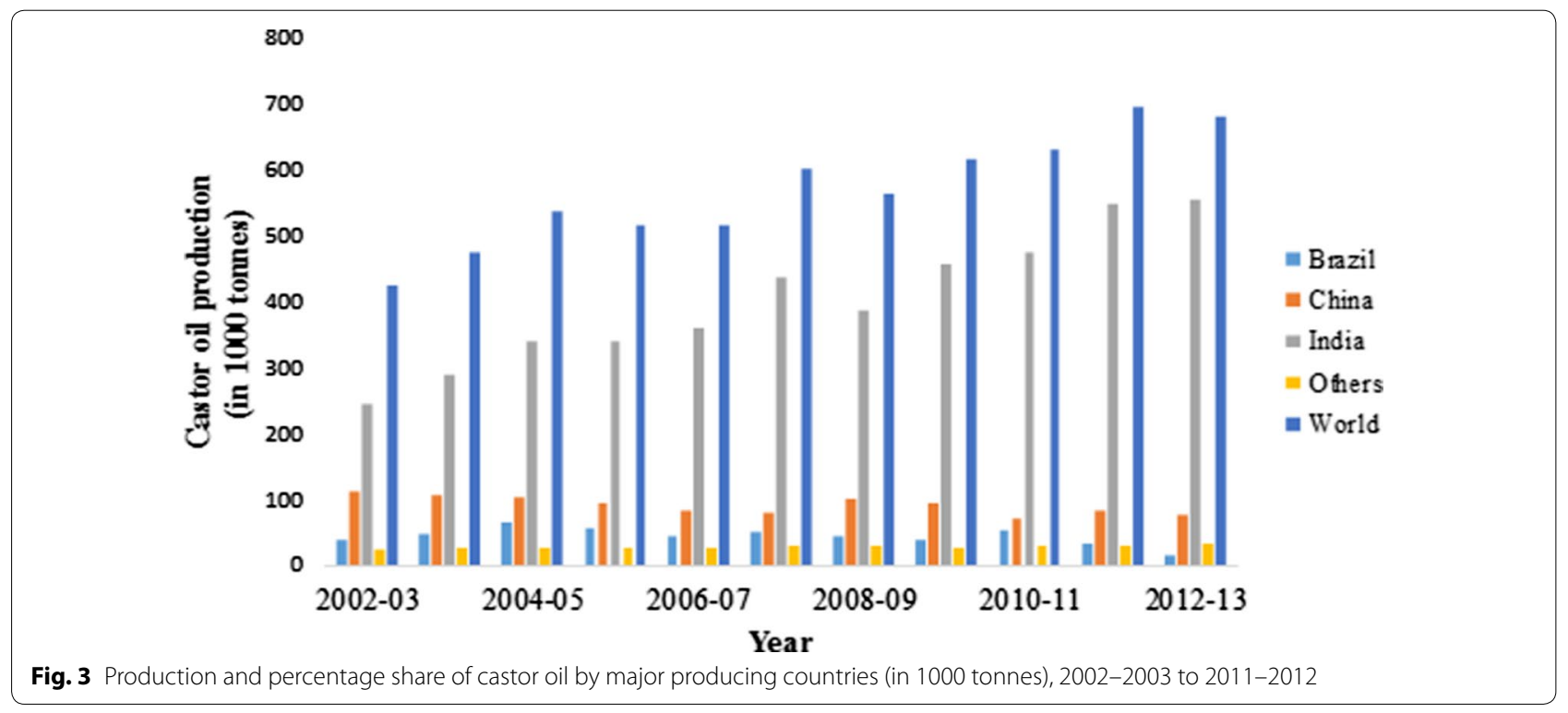


$89.5 \%$ Ricinoleic acid

$4.2 \%$ Linol eic acid

$3 \%$ Ol eic acid

$1 \%$ Stearic acid

$1 \%$ Palmitic acid

$0.7 \%$ Dihydroxystearic acid

$0.3 \%$ Linolenic acid

0.3\% Eicosanoic acid
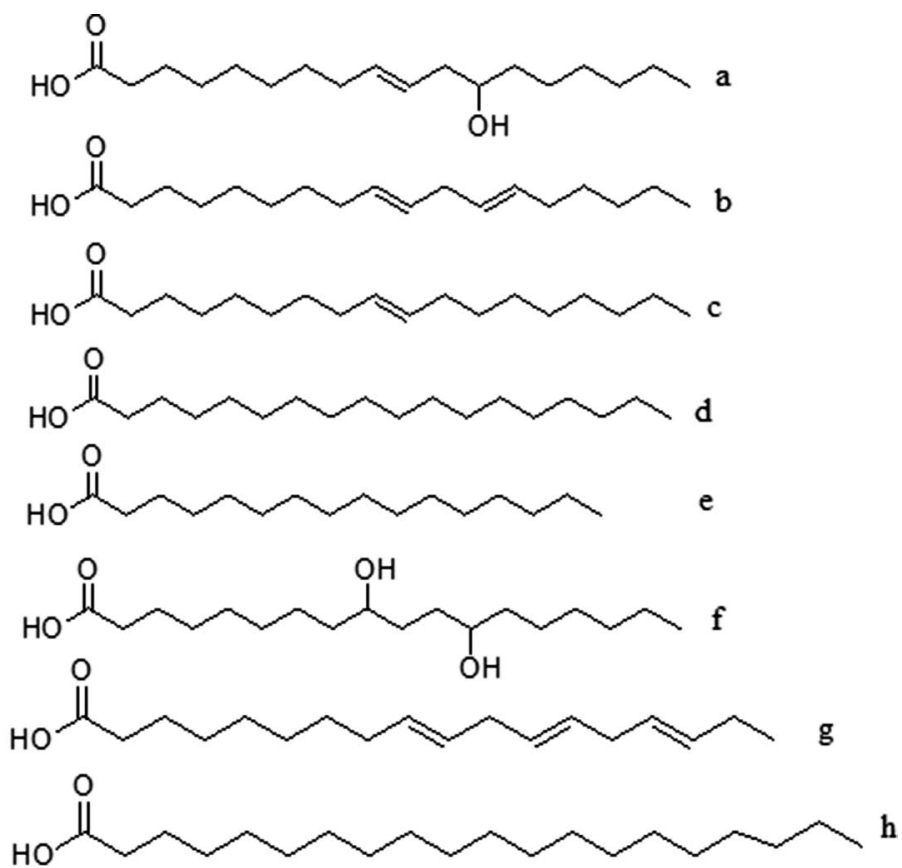

Fig. 4 Composition of castor oil fatty acids

\section{Chemical transformations of castor oil}

The unique properties and diverse applications of castor oil and its derivatives make castor oil popular and even more important among vegetable oils. The presence of ester linkage, a double bond and the hydroxyl group in ricinoleic acid favours the oil as a suitable renewable resource for many chemical reactions, modifications and transformations. The presence of carboxylic group for example, allow transformation of castor oil via several reactions such as esterification, amidation $[13,16,18]$ whereas the presence of a double bond, affords the transformation of the oil through reactions such as hydrogenation [16, 19], carbonylation [20] and epoxidation [21]. Furthermore, the hydroxyl functional group can be acetylated [21, 22] alkoxylated [23, 24] or removed by dehydration $[25,26]$ to increase the unsaturation of the oil. Catalytic dehydration leads into formation of a new double bond in the chain of ricinoleic acid resulting into a conjugated acid. This change imparts good flexibility, rapid drying, excellent color retention, and water resistance for protective coatings [26]. Both ring-opened glyceryl ricinoleates and epoxy alkyl ricinoleates functionalized castor oil derivatives have recently been prepared with very high yields [27]. The ring-opened glyceryl ricinoleates was achieved through catalytic ring opening and transesterification using epoxidized castor oil (ECO) as a raw material using Amberlyst 15 acid catalyst while the epoxy alkyl ricinoleates was achieved by transesterification of ECO with methanol using CaAl-layered double hydroxide base catalyst. Interestingly, the physical properties of these functionalized castor-based derivatives further demostrate the opportunity to design tailor-made materials suiting industrial needs from the oil.

Pyrolysis of castor oil cleaves the molecule to produce new useful compounds such as undecylenic acid and heptaldehyde. Addition of hydrogen bromide to the cleaved castor oil produces 11-bromo undecanoic, which upon reacting with ammonia, forms 11-aminoundecanoic acid; a monomer for nylon 11 polymer [28]. Generally, the three functional groups in ricinoleic acid provide multitude of possibilities of converting or modifying castor oil into many other useful products depending on the intended specific uses (Fig. 5).

Chemical transformations of castor oil into castor oil based products are discussed in the subsequent sections.

\section{Hydrogenation}

Addition of hydrogen to the unsaturated fatty acid in the presence of nickel or palladium catalyst transform the liquid ricinoleic acid into semi-solid saturated 12-hydroxystearic acid (Scheme 1).

The semi-solid saturated ricinoleic acid is a valuable material in industries and in resin or polymer mixtures. The oil has high melting point, improved storage qualities, taste, and odor. Moreover, the hydrogenated oil has an improved oxidative and thermal stability. A good 


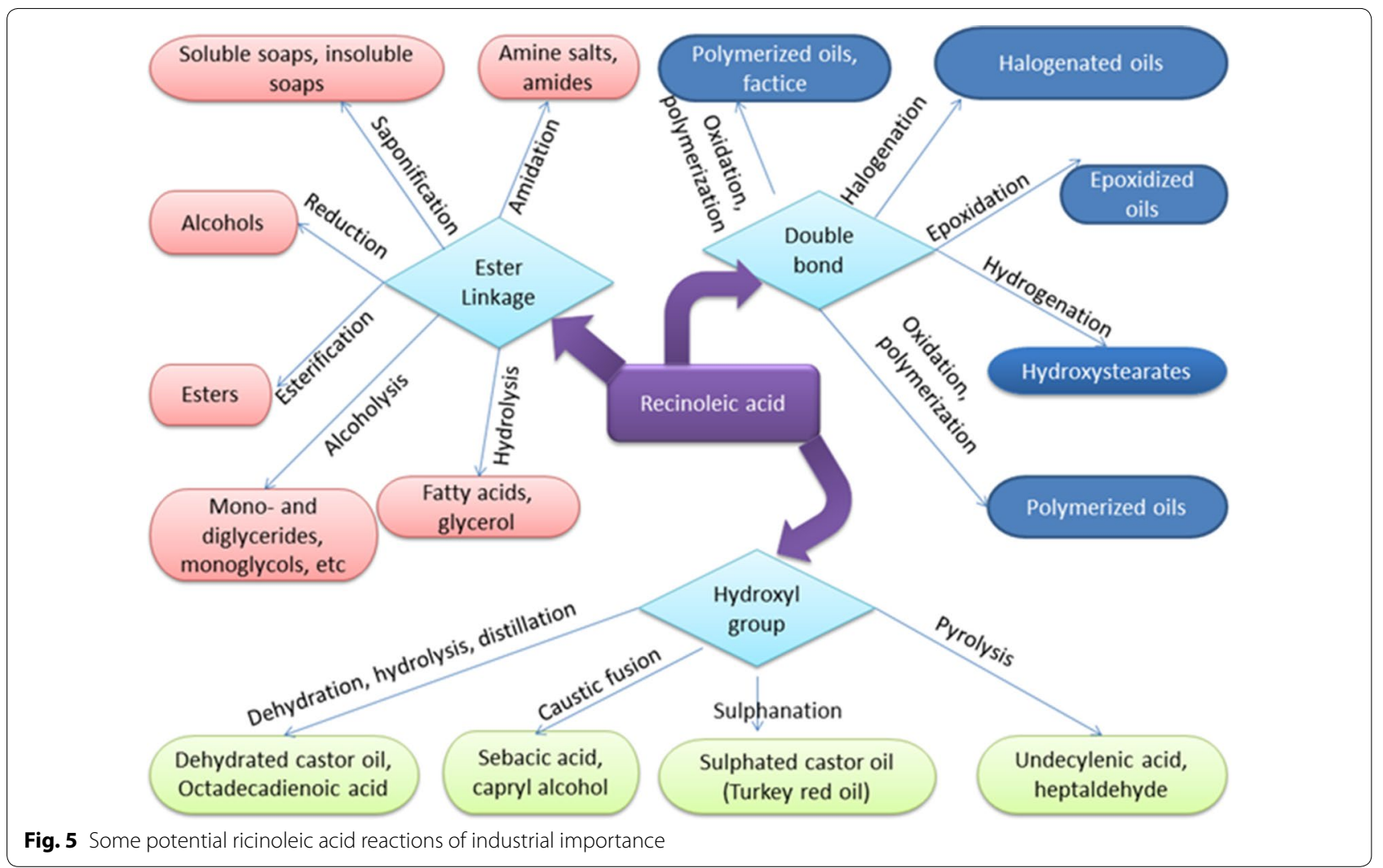

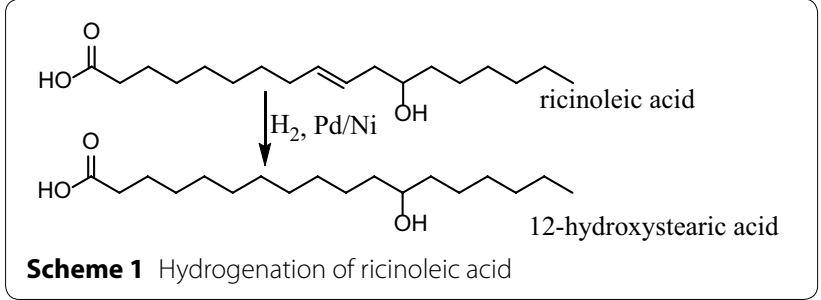

quality hydrogenated castor with high hydroxyl value and low iodine value is obtained at $423 \mathrm{~K} ; 1.034 \times 10^{6}$ $\mathrm{Pa}$; in $5 \mathrm{~h}$ with $2 \%$ (weight of oil) Raney nickel catalyst [28]. Hydrogenation of castor oil at low pressure (1.96$\left.2.45 \times 10^{5} \mathrm{~Pa}\right)$ and low temperature (398-408 $\left.\mathrm{K}\right)$ requires high catalyst concentration $[29,30]$.

Castor oil hydrogenation can also be done by catalytic transfer hydrogenation (CTH) (Scheme 2). Catalytic transfer hydrogenation has the advantage in that it can utilize organic molecules as hydrogen donors at ambient pressure and moderate temperatures. Moreover, no special reactors are required and the solvent is used as a hydrogen donor along with a selected catalyst. The CTH process using $\mathrm{Pd} / \mathrm{C}$ catalyst and different hydrogen donor solvents have also been reported for soy [31], sunflower [32], and castor [16, 33] oils.
Hydrogenated castor oil (HCO) is insoluble in water and in most organic solvents but it is soluble in hot organic solvents like ether and chloroform [29]. This insolubility is among good qualities that make $\mathrm{HCO}$ valuable for lubricant industries because of water resistance and retention of its lubricity. Moreover, the polarity and surface wetting properties of $\mathrm{HCO}$ are useful in cosmetics, hair dressing, solid lubricant, paint additives, manufacture of waxes, polishes, carbon paper, candles and crayons [28].

\section{Pyrolysis}

Pyrolysis is an increasingly popular option for converting biomass to solid, liquid, and gaseous fuels. It is a thermal treatment of a biomass in the absence of air that decomposes organic biomass into low molecular weight liquid, solid and gaseous products [34]. The absence of air during pyrolysis prevents the combustion of biomass into carbon dioxide. Pyrolysis is normally done at medium to high temperature (623-1023 K) in which the biomass is degraded to yield pyrolysis oil or bio-oil. An extensive review on pyrolysis of different vegetable oils such as tung oil, sunflower oil, canola oil, soybean oil, palm oil, macauba fruit oil, cooking oil, palm oils, soybean, and castor oils have been reported [35]. Generally, the process can be done by either direct thermal cracking or by a combination of thermal and catalytic cracking. Reaction 


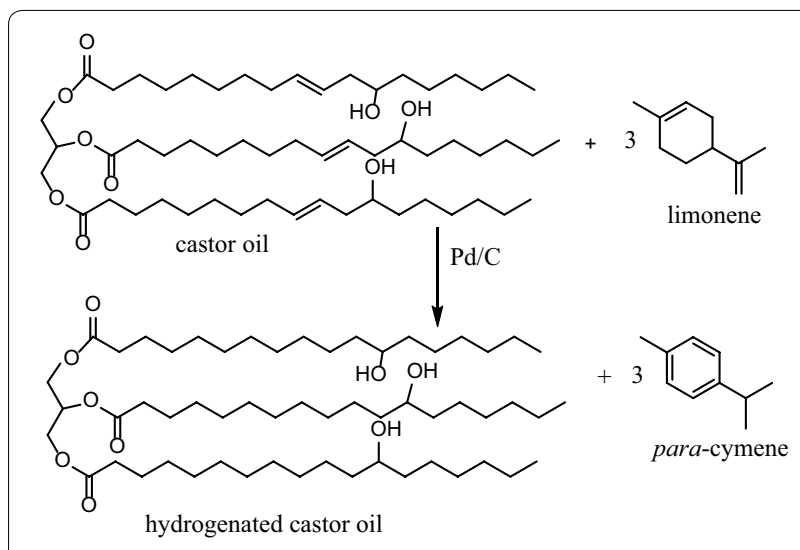

Scheme 2 Catalytic transfer hydrogenation of castor oil

products depend on the catalyst type and the reaction conditions and can range from diesel like to gasoline like fractions. Pyrolysis of triglycerides represent an alternative method for producing renewable bio-based products suitable for use in fuel and chemical applications. Pyrolysis of castor oil for example, at $623 \mathrm{~K}$ with $20 \mathrm{~min}$ residence time and $1.47-1.96 \times 10^{6} \mathrm{~Pa}$ initial hydrogen pressure, produces castor bio-oil $[35,36]$. Moreover, methanolysis of castor oil yields methyl ricinoleate which upon pyrolysis under reduced pressure $\left(6.0 \times 10^{3}\right.$ $\mathrm{Pa})$, at about $973 \mathrm{~K}$, produces heptaldehyde and undecylenic acid (Scheme 2) $[28,36]$. The two products are vital intermediates in the perfumery, pharmaceutical and polymeric formulations. Heptaldehyde is also an organic solvent for various polymers and a source of emulsifier, plasticizers and insecticides. For the undecylenic acid, it serves as a source of bactericides and fungicides but also further reactions on the acid (Scheme 3) can produce monomers for the formation of nylon $11[28,37]$.

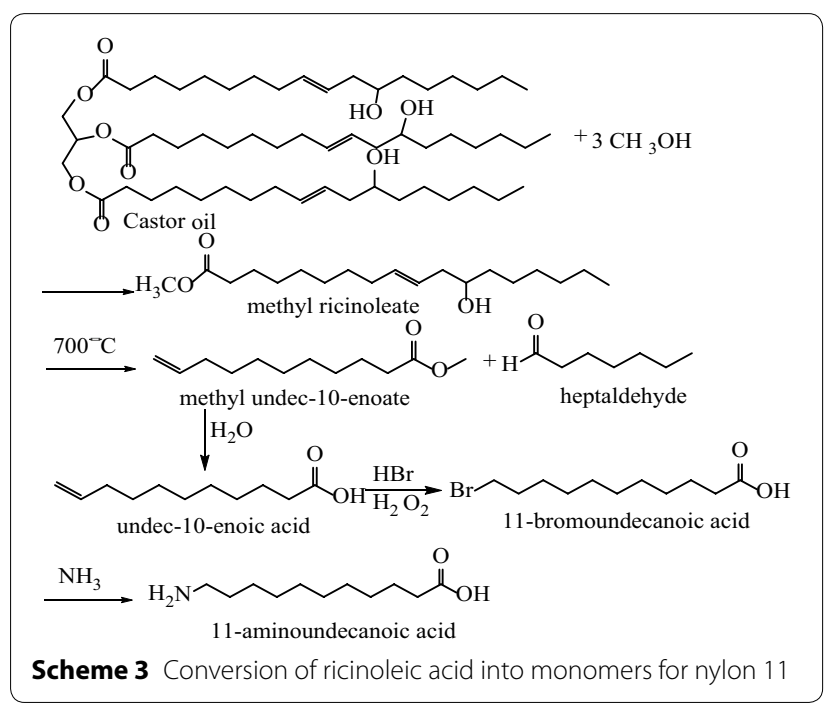

\section{Hydrolysis of castor oil}

Hydrolysis of castor oil by slow addition of castor oil to $80 \%$ caustic solution (sodium hydroxide) produces ricinoleic acid and glycerol. Upon heating at $523 \mathrm{~K}$ in the presence of $\mathrm{NaOH}$, sebacic acid (a 10 carbon dicarboxylic acid) and capryl alcohol (2-octanol) are produced (Scheme 4).

Both sebacic acid and capryl alcohol have many uses. The alcohol finds its uses as plasticizer, as a solvent, dehydrater, antibubbling agent and also as a floatation agent in coal industry [36]. The esters of sebacic acid on the other hand are plasticizers for vinyl resins and are also used in the manufacture of dioctyl sebacate (DOS), a jet lubricant and lubricant in air cooled combustion motors $[1,38]$ Furthermore; sebacic acid is used as a monomer where it reacts with hexamethylenediamine to produce nylon 6-10 [38].

\section{Dehydration}

The dehydration of ricinoleic acid is an acid catalysed reaction which removes the hydroxyl group in the form of water to introduce a new double bond. The reaction results into the production of both non-conjugated linoleic acid and the conjugated linoleic acid (Scheme 5) [37]. The dehydration of castor oil is usually done at temperatures above $473 \mathrm{~K}$ in the presence of an acid catalyst such as concentrated sulphuric acid, phosphoric acid, p-toluenesulfonic acid, sodium bisulfate, or activated clays under inert atmosphere [25]. The formed linoleic acids have various industrial applications including the production of protective coating, vanishes, lubricants, soaps, paints, inks, manufacture of alkyd resins, coatings, appliance finishes and primers $[1,39,40]$. The linoleic acids are also basic ingredients in racing motor oil for high-performance automobile motorcycle engines.

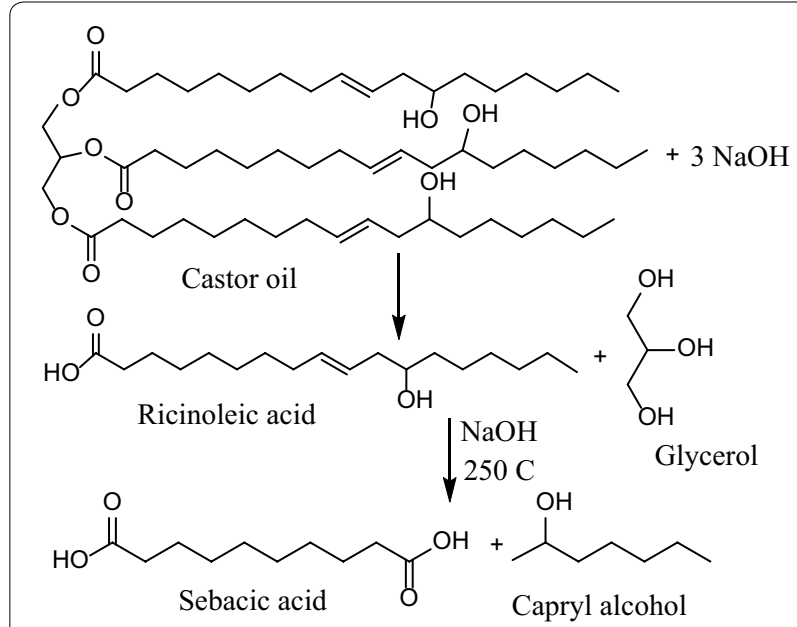

Scheme 4 Conversion of ricinoleic acid into sebacic acid and capryl alcohol 


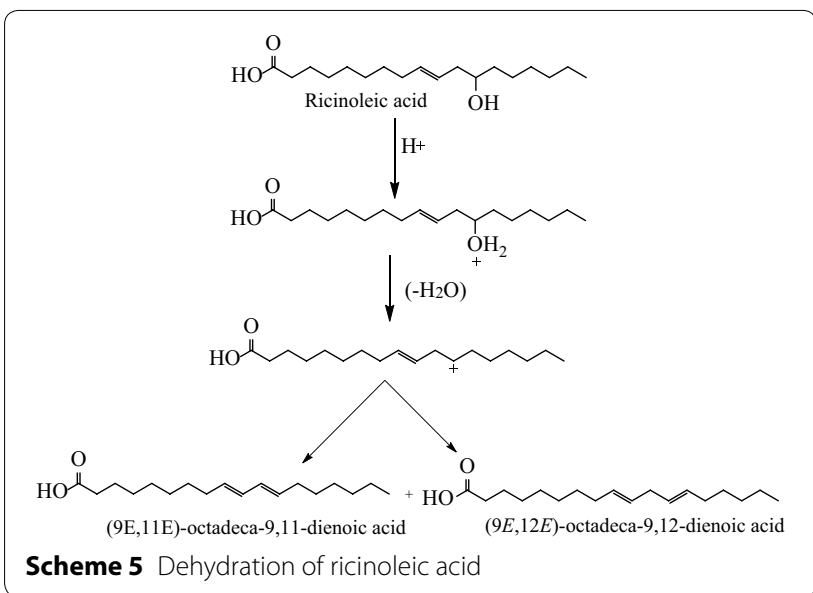

\section{Transesterification}

Transesterification of vegetable oils refer to the breaking down of vegetable oil molecules by reacting an alcohol with an ester (in the vegetable oil) in which the glycerol functional group from the triglyceride is removed and replaced by an alcohol [18, 41] producing a biodiesel (Scheme 6). The catalysts used in the transesterification are often acid catalysts (e.g. $\mathrm{HCl}, \mathrm{H}_{2} \mathrm{SO}_{4}, \mathrm{H}_{3} \mathrm{PO}_{4}$ ) even though base catalysts (e.g. $\mathrm{KOH}, \mathrm{NaOH}, \mathrm{CH}_{3} \mathrm{OK}$, $\left.\left(\mathrm{CH}_{3} \mathrm{O}\right)_{2} \mathrm{Ca}, \mathrm{CaO}\right)$ or heterogeneous catalysts such as zeolites or enzyme catalysts are also used [40, 41].

Transesterification reactions are reversible and therefore an excess alcohol is usually used to shift the equilibrium to the formation of the biodiesel. Generally transesterification reduces the molecular weight and thus reducing the viscosity of the castor oil which is not required in the biodiesel [42]. Transesterification also increases the volatility while maintaining the cetane number and heating value of the biodiesel [43, 44].

The increased production of biodiesel from vegetable oils has led to the overproduction of glycerol. For instance, Worldwide crude glycerol derived from biodiesel conversion has increased from 200, 000 tonnes in 2004 to 1.224 million tonnes in 2008 [45]. Due to this overproduction of glycerol, scientists are finding new applications for refined and crude glycerol. Examples of such applications include but are not limited to the use of crude glycerol in animal feeds both for ruminants and non ruminants animals [46]. Feed stock for fermentative production 1,3-propanediol by Klebsiella pneumonia [47], biosynthesis of citric acid from crude glycerol by Yarrowia lipolytica ACA-DC 50109 [46] and fermentative conversion of crude glycerol to hydrogen by the bacterium Rhodopseudomonas palustris [48, 49, 50]. Glycerol can also be a good source of various solvents such as propylene glycols, glycerol ethers and esters. Crude glycerol

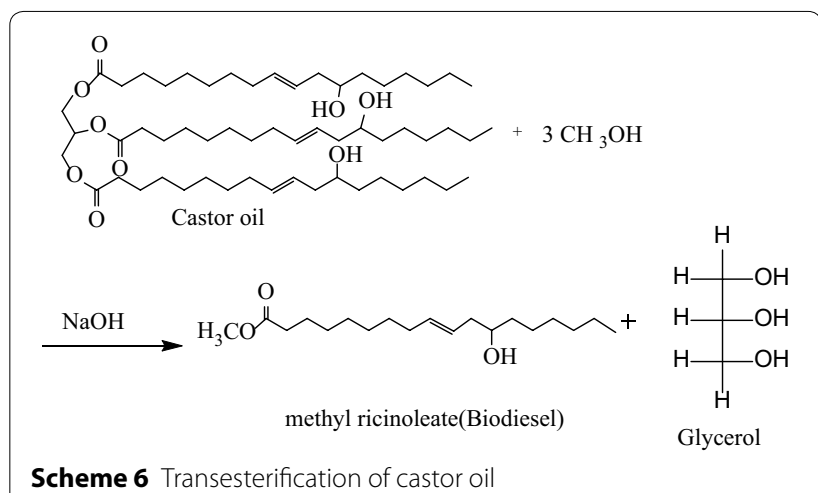

(without any purification) is a green solvent and a reducing agent for metal-catalyzed transfer hydrogenation reactions and nanoparticles formation [51]. Glycerol have also shown potential as a high-boiling-point organic solvent to enhance enzymatic hydrolysis of lignocellulosic biomass during atmospheric autocatalytic organosolvent pre-treatment [52]. Synthesis of aliphatic polyesters from glycerol by reacting it with adipic acid (Scheme 7) is also reported elsewhere [53].

\section{Sulphation of castor oil}

Sulphation refers to the introduction of $\mathrm{SO}_{3}$ group into an organic compound to produce the characteristic $\mathrm{C}-\mathrm{OSO}_{3}$ configuration. Sulphation of castor oil produces sulphuric acid esters (Turkey-red oil) in which the hydroxyl group of ricinoleic acid has been esterified (Scheme 8) [54]. The reaction is done by treating raw castor oil at room temperature or at temperature less than 308 Kwith concentrated sulphuric acid for 3-4 h.

Turkey-red oil is widely used in textile and cosmetics industries by producing synthetic detergents in the recipes/formulations of lubricants, softeners, and dyes. In addition, Turkey-red oil is an active wetting agent in dyeing and in finishing of (Scheme 8) cotton and linen. It is also used in bath oil recipes along with natural or synthetic fragrance or essential oils or in shampoos [55].

\section{Castor oil based polymers}

The depletion of fossil fuels and environmental issues has necessitated researchers to focus their attention and efforts to the utilization of renewable resources as raw materials for the synthesis of polymeric materials. Biobased polymers offer a number of advantages over polymers prepared from petroleum-based monomers as they are cheaper, readily available from renewable natural resources and they possess comparable or better properties. Some bio-based polymers are biodegradable, nontoxic and have low carbon footprints [56]. Polyamides, 


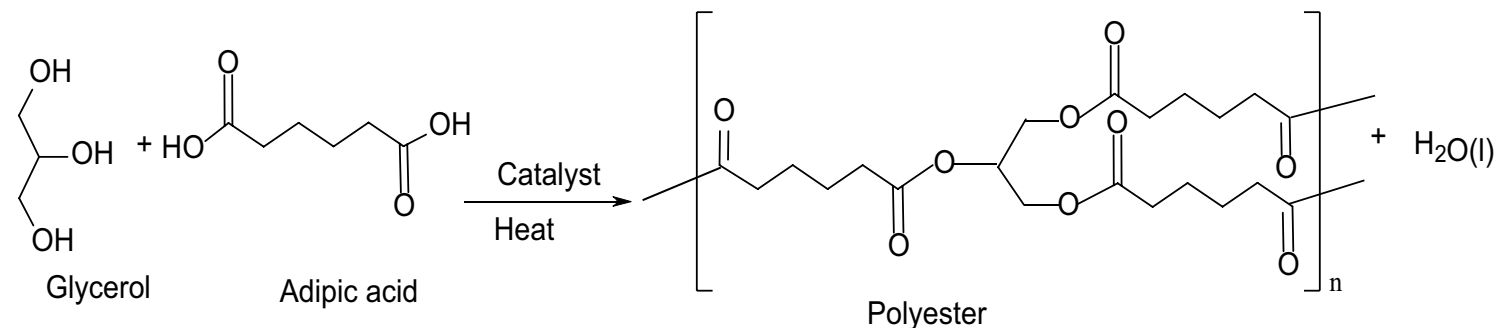

Scheme 7 Synthesis of aliphatic polyester from glycerol and adipic acid<smiles>CCCCCCC(O)CC=CCCCCCCCCC(=O)OC(COC(=O)CCCCCCCC=CCC(O)CCCCCC)COC(=O)CCCCCCCC=CCC(O)CCCCCC</smiles><smiles>CCCCCCC(C/C=C/CCCCCCCCC(=O)OCC(COC(=O)CCCCCCC/C=C/CC(CCCCCC)OS(=O)(=O)O)OC(=O)CCCCCCCC(CCCCCC)OS(=O)(=O)O)OS(=O)(=O)O</smiles>

Sulphated castor oil(Turkey red oil)

Scheme 8 Sulphation of castor oil into Turkey red oil

polyethers, polyesters and interpenetrating polymer networks have been synthesized from castor oil [10, 39, 57-61]. Most of these castor oil polymers are particularly on the production of polyurethanes, polyamides and polyesters. In another development, the synthesis of interpenetrating polymer networks based on polyol modified castor oil polyurethane and poly(2-hydroxyethylmethacrylate) has been reported [58].

Ozonolysis of castor oil followed by reduction (Scheme 9) produces triglycerides of 9-carbon fatty acids with terminal hydroxyl groups.

The 9-carbon fatty acids can be used as monomers in the preparation of condensation polymers such as polyurethane, polyethers and polyesters.

\section{Polyurethane from castor oil monomers}

Polyurethanes (PU) are polymers containing urethane linkages (-NHCOO-) in the main polymer chain. They are among the most important and versatile classes of polymers as they can vary from thermoplastic to thermosetting materials [62-68]. The industrial production of polyurethanes is normally accomplished through the polyaddition reaction between organic isocyanates and compounds containing active hydroxyl groups, such as polyols [68]. From an environmental viewpoint, this method is not advantageous because it uses highly reactive and toxic isocyanates, which are commonly produced from an even more dangerous component, phosgene [69]. In the search for green routes to the key polyurethane intermediates, fats and oils offer important alternatives for the production of diols, polyols, and other oxo chemicals, thus, enabling to substitute petrochemicals [20]. Environmentally friendly production of polyurethanes is achieved using plant-derived diols and diisocyanates or using nonisocyanate chemistries [70]. Polyurethanes prepared from vegetable oils exhibit a number of excellent properties that are attributable to its hydrophobicity. Castor oil as a source of polyols, is increasingly finding application in the manufacture of polyurethane. Polyurethane networks based on castor oil as a renewable resource polyol and poly(ethylene glycol) (PEG) with tunable biodegradation rates for biomedical implants and tissue engineering is documented elsewhere [10]. The synthesis involved the reaction of 

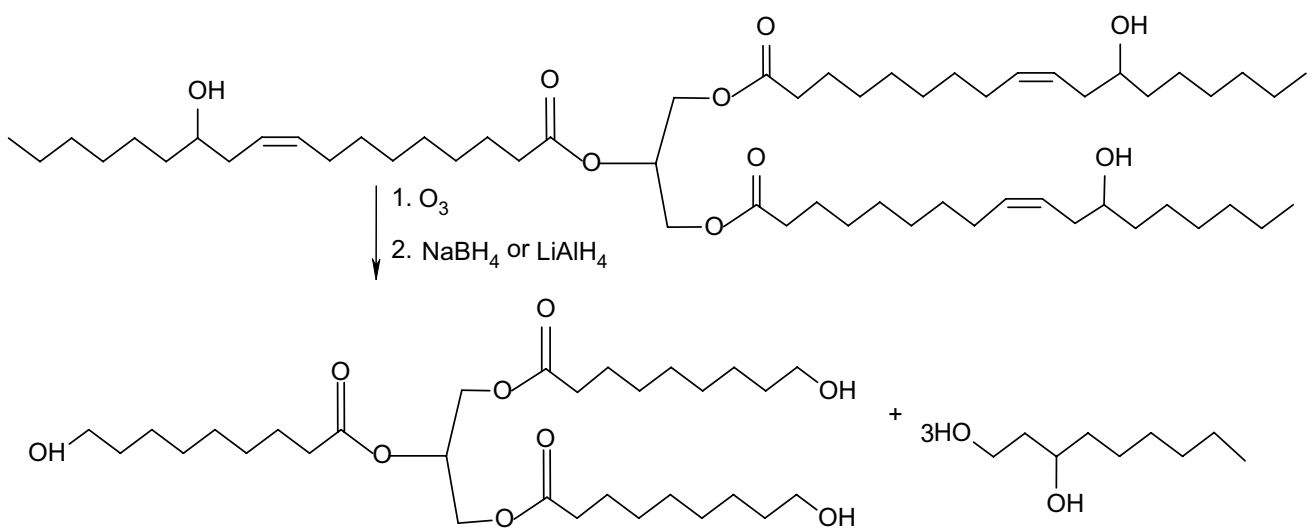

Scheme 9 Ozonolysis and reduction of castor oil

epoxy-terminated polyurethane prepolymers (EPUs) from castor oil with 1,6-hexamethylene diamine curing agent. This is interesting given that there are a limited number of naturally occurring triglycerides which contain the unreacted hydroxyl groups and castor oil being the only commercially-available natural oil polyol that is produced directly from a plant source as all other natural oil polyols require chemical modification prior to their use [63]. Polyurethane derived from castor oil find their applications in areas such as biomedical implants, coatings, cast elastomers, thermoplastic elastomers, rigid foams, semi-rigid foams, sealants, adhesives and flexible foams.

\section{Methoxycarbonylation of undecylenic acid derived from castor oil}

Methoxycarbonylation of plant oils to form diesters is a crucial discovery towards making polymer precursors from plant oils. $\mathrm{Pd}_{2}(\mathrm{dba})_{3}, 1,2$-bis(ditertiarybutyl phosphinomethyl)benzene (DTBPMB), and methane sulfonic acid in methanol have been reported to be an effective catalytic system for making linear diesters from plant oils $[20,71,72]$. Subjecting plant oils to this catalytic system, the double bond located at the center of the molecule is isomerized to the terminal end at $\omega$ position with the ester functionality and is trapped by carbonylation to form $\alpha-\omega$ diester (Scheme 10) [20]. Undecylenic acid with the double bond in the terminal position is a product of pyrolysis of ricinoleic acid from castor oil.
Methoxycarbonylation of undecenoic acid or esters produces dimethyl 1,12-dodecanedioate, which is a component of Nylon-12,12.

Overall, growth of biopolymers from castor oil industries makes the oil potential for it to play a much larger role in the world economy on polymers and to humanity.

\section{Green synthesis of nanomaterials using castor oil or ricinoleic acid}

The high percentage of ricinoleic acid and its structural features makes castor oil capable of forming covalent dative bonds with active surface dangling orbitals of chalcogenides quantum dots. Green synthesis of chalcogenides nanomaterials using castor oil and its isolate ricinoleic acid as eco-friendly bio-based capping agents have recently been reported [73-79]. This is environmentally interesting because the use of castor oil and ricinoleic acid as both capping and dispersing agents, eliminate the need for the use of air-sensitive, toxic and expensive chemicals such as trioctylphosphine (TOP), trioctylphosphine oxide (TOPO) and alkyl amines. It is worth noting that the boiling points of castor oil and ricinoleic acid are 586 and $685 \mathrm{~K}$, respectively and thus they are simple to work with since they are liquid at room temperature. Literature reports the high ability of castor oil to prevent agglomeration of the synthesized nanoparticles due to the presence of long-chain hydrophobic moieties, thus forming ultra-small, well dispersed and stable quantum dots for a long period of time [76-79].<smiles>COC(=O)CCCCCCCCCC=C([18O])C(=O)O</smiles>

Scheme 10 Synthesis of dimethyl 1,12-dodecanedioate from methyl undec-10-enoate 
Some of these nanomaterials synthesized using castor oil or ricinoleic acid can be suitable for biological and medical applications because no toxic reagents are used in their preparation [80].

\section{Conclusions}

The diversity of chemicals and products produced from castor oil has proven that castor is an important and potential non-edible oilseed crop. The great utilitarian value in industry, agriculture, cosmetics and pharmaceutical sectors is a direct proof that castor oil is a potential bio-based starting material. The presence of a hydroxyl group, carboxylate and double bonds in the ricinoleic acid, imparts unique properties for the derivatization of castor oil into vital industrial raw materials. It has been shown how castor oil can be used as a renewable bio-based raw material for the production a multitude of functional materials. It is equally noted that the diverse possibilities of castor oil transformation mainly depend on the presence of the three functional groups. This review has further shown that castor oil is a potential alternative to petroleum-based starting materials for the production of wide range of industrial materials. It can also be seen that apart from the oil's unique chemical structure and environmental considerations, the worldwide growth in castor oil demand is due to its easy availability, low cost, non-food competition. It has been observed in the discussion that castor oil is more than just a bio-based raw material in great demand by the chemical industries but its use as a fuel is also seen when transesterification is done. The worldwide increase in the production of castor seeds and castor oil testifies the huge potential as a green bio-resource for chemical transformations because castor oil can be used as the starting material for producing a wide range of end-products.

\section{Authors' information}

Dr. E. B. Mubofu obtained his Ph.D. in June 2002 from the University of York, UK where he worked on novel environmentally benign supported palladium catalysts under the supervision of Prof. Dr. James H. Clark and Dr. Duncan Macqurrie in the green chemistry group. He was a postdoctoral fellow for 2 years (2001-2003) at the University of Groningen, Stratingh Institute. In his postdoctoral tenure in the physical organic chemistry group; he worked on the use of water as an alternative cleaner and green solvent for performing Lewis acid catalysed Diels-Alder reactions under the guidance of Prof. Dr. Jan Engberts. In December 2003, he returned to Tanzania and joined the Chemistry Department, University of Dar es Salaam as a lecturer. He is now a senior lecturer since 2008 and is the chairman of the Department since 2012. EBM research interests are on Green Chemistry, nanomaterials and catalysis. He is involved with the novel chemical modification of nanomaterial surfaces and their application to different reactions, such as acid-catalysed reactions, water treatment, drug-delivery, catalytic oxidations and carbon-carbon bond forming transformations. He is heavily involved on the synthesis of nanomaterials using locally and cheaply available renewable bio-based capping agents for various applications. He has developed several palladium/copper heterogeneous catalysts (metal and biocatalysts) using chemically modified MTS with cashew nut shell liquid (CNSL) surfactant. He has authored or co-authored several publications in international journals on the use of renewable resources to generate functional materials.

\section{Acknowledgements}

I would like to acknowledge the National Research Foundation and the Commission for Science and Technology through NRF-COSTECH project for partial financial support to this work. Mr. James Mgaya and Mr. Athumani Omari are acknowledged for their assistance in writing the manuscript and for their technical assistance.

\section{Competing interests}

The author declares no competing interests.

Received: 23 November 2015 Accepted: 13 June 2016

Published online: 15 July 2016

\section{References}

1. Ogunniyi DS (2006) Castor oil: a vital industrial raw material. Bioresour Technol 97:1086-1089

2. Bagali S, Shridhar K, Beena KV, Anita VM, Paramjeet BK (2010) Optimization and characterization of castor seed oil. Leornard J Sci 17:1-10

3. Salihu BZ, Gana AK, Apuyor B (2014) Castor oil plant (Ricinus communis L.): botany, ecology and uses. IJSR 3:1333-1341

4. Severino LS, Auld DL, Baldanz M, Candido MJD, Chen G, Crosby W, Tan D, He X, Lakshmamma P, Lavanya C, Machado OLT, Mielke T, Milan M, Miller TD, Morris JB, Morse SA, Narvas AA, Soares DJ, Sofiatt V, Wang ML, Zanotto MD, Zieler HA (2012) Review on the challenges for increased production of castor. Agron J 104:853-880

5. Pavaskar M, Kshirsagar A (2013) Global castor oil and Indian monopoly. Financial Vis 1:15-19

6. James S (2016) Castor oil and derivatives market trend, growth, research and analysis to 2020. https://www.linkedin.com/pulse/castor-oil-derivatives-market-trend-growth-research-analysis-james. Accessed $18 \mathrm{Apr}$ 2016

7. Grand view research. Castor oil and derivatives market analysis by product (sebacic acid, undecylenic acid, castor wax, dehydrated castor oil), by application (lubricants, surface coatings, biodiesel, cosmetics \& pharmaceuticals, plastics \& resins) and segment forecasts to 2020. http:// www.grandviewresearch.com/industry-analysis/castor-oil-derivativesindustry. Accessed 18 Apr 2016

8. Dasari SR, Goud VV (2013) Comparative extraction of castor seed oil using polar and non polar solvents. IJCET Spec Issue 1:121-123

9. Biermann U, Bornscheuer U, Meier MAR, Metzger JO, Schfer HJ (2011) Oils and fats as renewable raw materials in chemistry. Angew Chem Int Ed 50:3854-3871

10. Yeganeh $H$, Hojati-Talemi P (2007) Preparation and properties of novel biodegradable polyurethane networks based on castor oil and poly(ethylene glycol). Polym Degrad Stab 92(3):480-489

11. Gana AK, Yusuf AF, Apuyor B (2013) Castor oil plant and its potentials in transformation and industrialization of under developing nations in the world. Adv J Agric Res 1:72-79

12. Imankulov N (2012) Preparation and research on properties of castor oil as a diesel fuel additive. ATI 6:30-37

13. G. R. O'Shea Company, www.groshea.com, August 2015

14. Salimon J, Noor DAM, Nazrizawati AT, Firdaus MYM, Noraishah A (2010) Fatty acid composition and physicochemical properties of Malaysian castor bean Ricinus communis L. seed oil. Sains Malaysiana 39:761-764

15. Nangbes JG, Nvau JB, Buba WM, Zukdimma AN (2013) Extraction and characterization of castor (Ricinus Communis) seed oil. IJES 2:105-109

16. Alwaseem H, Donahue CJ, Marincean S (2014) Catalytic transfer hydrogenation of castor oil. J Chem Educ 91:575-578

17. Omari A, Mgani QA, Mubofu EB (2015) Fatty acid profile and physicochemical parameters of castor oils in Tanzania. Green Sustain Chem 16:154

18. Deshpande DP, Haral SS, Gandhi SS, Ganvir VN (2012) Transesterification of castor oil. ISCA J Eng Sci 1:2-7

19. Sreenivasan B, Kamath NR, Kane JG (1957) Studies on castor oil II. Hydrogenation of castor oil. JACS 34:302-307

20. Marc RL, Furst MRL, Le Goff R, Quinzler D, Mecking S, Botting CH, ColeHamilton DJC (2012) Polymer precursors from catalytic reactions of natural oils. Green Chem 14:472-477 
21. Sinadinovic-Fiser S, Jankovic M, Borota O (2012) Epoxidation of castor oil with peracetic acid formed in situ in the presence of an ion exchange resin. Chem Eng Process 62:106-113

22. Grummitt O, Fleming H (1945) Acetylated castor oil, preparation and thermal decomposition. Ind Eng Chem 37:485-491

23. Mukherjea RN, Saha KK, Sanyal SK (1978) Plasticizing effect of acetylated castor oil on castor oil-based, moisture-cured polyurethane film. J Am Oil Chem Soc 55:653-656

24. Zhang Q, Sun Y, Zhi L, Zhang Y, Di Serio M (2015) Properties of ethoxylated castor oil acid methyl esters prepared by ethoxylation over an alkaline catalyst. J Surfactants Deterg 18:365-370

25. Bhowmick DN, Sarma SAN (1977) Dehydration of castor oil. Ind Eng Chem Prod Res Dev 16:107-111

26. Nezihe A, Elif D, Yllmaz O, Tuncer EA (2011) Microwave heating application to produce dehydrated castor oil. Ind Eng Chem Res 50:398-403

27. Sankaranarayanan S, Srinivasan K (2015) Preparation of functionalized castor oil derivatives with tunable physical properties using heterogeneous acid and base catalysts. RSC Adv 5:50289-50297

28. Naughton FC (1974) Production, chemistry and commercial applications of various chemicals from castor oil. J Am Oil Chem Soc 51:65-71

29. Rao HS, Chari KS, Aggarwal JS (1962) Hyrogenation of castor oil: part I-Influence of variables on hydrogenation efficiency. J Sci Industr Res 21D:89-92

30. Trivedi RK, Vasishtha AK (1988) Low pressure hydrogenation of castor oil. J Am Oil Chem Soc 65:1467-1469

31. Smidovnik A, Stimac A, Kobe J (1992) Catalytic transfer hydrogenation of soybean oil. J Am Oil Chem Soc 69:405-409

32. Devi BL, Karuna MSL, Rao KN, Saiprasad PS, Prasad RBN (2003) Microwaveassisted catalytic transfer hydrogenation of sunflower oil. J Am Oil Chem Soc 80:1003-1005

33. Kulkarni Mangesh G, Sawant Sudhirprakash B (2003) Some physical properties of castor oil esters and hydrogenated castor oil esters. Eur J Lip Sci Technol 105:214-218

34. Lin CSK, Mubofu EB, Budarin V, Lam G, Kwan D (2015) Pretreatment and thermo-chemical and biological processing of biomass. In: Clark J, Deswarte F (eds) Introduction to chemicals from biomass, 2nd edn. Wiley, New York, pp 53-88

35. Maher KD, Bressler DC (2007) Pyrolysis of triglyceride materials for the production of renewable fuels and chemicals. Bioresour Technol 98:2351-2368

36. Datta S, Chavan P, Saha S, Sahu G, Mall BK (2011) Synthesis of biodiesel by pyrolysis of castor oil. Asian J Chem 23:2614-2618

37. Lligadas G, Ronda JC, Cadiz V (2010) Oleic and undecylenic acids as renewable feedstocks in the synthesis of polyols and polyurethanes. Polymers 2:440-453

38. Vasishtha AK, Trivedi RK, Das G (1990) Sebasic acid and 2-octanol from castor oil. J Am Oil Chem Soc 67:333-337

39. Mutlu H, Meir MAR (2010) Castor oil as a renewable resource for chemical industry. Eur J Lipid Sci Technol 112:10-30

40. Ramamurthi S, Manohar V, Mani VVS (1998) Characterization of fatty acid isomers in dehydrated castor oil by gas chromatography and gas chromatography-mass spectrometry techniques. J Am Oil Chem Soc 75:297-1303

41. Nakarmi A, Joshi SA (2014) Study on castor oil and its conversion into biodiesel by transesterification method. NJST 15:45-52

42. Encinar JM, Gonzalez JF, Pardal A, Martinez G (2010) Transesterification of rapeseed oil with methanol in the presence of various co-solvents, Venice Third International Symposium on Energy from Biomass and Waste

43. Sreenivas P, Mamilla VR, Sekhar KC (2011) Development of biodiesel from castor oil. IJES 1:192-197

44. Bello El, Mogaji TS, Agge M (2011) The effects of transesterification on selected fuel properties of three vegetable oils. J Mech Eng Res 3:218-225

45. Yang F, Hanna MA, Sun R (2012) Value-added uses for crude glycerol, a by-product of biodiesel production. Biotechnol Biofuels 5:13

46. Nitayavardhana S, Khanal SK (2011) Biodiesel-derived crude glycerol bioconversion to animal feed: a sustainable option for a biodiesel refinery. Bioresour Technol 102:5808-5814

47. Jalasutram V, Jetty A (2011) Optimization of 1, 3-Propanediol production by Klebsiella pneumoniae 141B using Taguchi methodology: improvement in production by cofermentation studies. Res Biotechnol 2:90-104
48. Rywinska A, Rymowicz W, Marcinkiewicz M (2010) Valorization of raw glycerol for citric acid production by Yarrowia lipolytica yeast. Electron J Biotechnol 13:1-9

49. Satpathy P, Thosar A, Rajan AP (2014) Green technology for glycerol waste from biodiesel plant. Int J Curr Microbiol App Sci 3:730-739

50. Li C, Lesnik KL, Liu H (2013) Microbial conversion of waste glycerol from biodiesel production into value-added products. Energies 6:4739-4768

51. Diaz-Alvarez AE, Cadierno V (2013) Glycerol: a promising green solvent and reducing agent for metal-catalyzed transfer hydrogenation reactions and nanoparticles formation. Appl Sci 3:55-69

52. Zhao X, Cheng K, Liu D (2009) Organosolv pretreatment of lignocellulosic biomass for enzymatic hydrolysis. Appl Microbiol Biotechnol 82:815-827

53. Brioude MM, Guimarãesa DM, Fiúza RP, Prado LASA, Boaventura JS, José NM (2007) Synthesis and characterization of aliphatic polyesters from glycerol, by-product of bio-diesel production and adipic acid. Mater Res 10:335-339

54. Rangarajan S, Palaniappan NP (1958) Catalysts in sulfation of castor oil. Ind Eng Chem 50:1787-1788

55. Santhanam N, Balu M, Sreevatsan S Production and uses of key castor oil oleochemicals. Comprehensive castor oil report. www.castoroil. Accessed 17 Feb 2015

56. Nayak PL (2000) Natural oil-based polymers. J Macromol Sci Polym Rev 40:1-21

57. Mallu P, Siddaramaiah V, Somashekar R (2000) Synthesis and characterization of castor oil-based polyurethane-polyacrylonitrile interpenetrating polymer networks. Bull Mater Sci 23:413-415

58. Prashantha K, Pai KVK, Sherigara BS, Prasannakumar S (2001) Interpenetrating polymer networks based on polyol modified castor oil polyurethane and poly (2-hydroxyethylmethacrylate): synthesis, chemical, mechanical and thermal properties. Bull Mater Sci 24:535-538

59. O'Lenick AJ, LaVay C (2002) Castor polyester for personal care. Cosmet Toiletr 117:59-64

60. O'Lenick AJ, Dacula GA, LaVay C, Riverside CT (2002) Polymeric castor polyesters. United States Pat US 6(342):527

61. Sokolsky-Papkov M, Shikanov S, Kumar N, Vaisman B, Domb AJ (2008) Fatty acid based biodegradable polymers-synthesis and applications. Israel Chem Soc 23:12-17

62. Tabandeh S, Taromi FA, Nazockdast H (2014) Flexible polyurethane nanocomposite foam: synthesis and properties. Polym Sci Ser B 56:681-685

63. Ogunniyi DS, Fakayejo WRO (1996) Preparation and properties of polyurethane foams from toluene diisocyanate and mixtures of castor oil and polyol. Iran Polym J 5:56-59

64. Barikani M, Barmar M (1996) Thermoplastic polyurethane elastomers: synthesis, and study of effective structural parameters. Iran Polym J 5:231-235

65. Tran RT, Thevenot P, Gyawali D, Chiao J, Tang L, Yang J (2010) Synthesis and characterization of a biodegradable elastomers featuring a dual crosslinking mechanism. Soft Matter 6:2449-2461

66. Ismail EA, Motawie AM, Sadek EM (2011) Synthesis and characterization of polyurethane coatings based on soybean oil-polyester polyols. Egypt J Pet 20:1-8

67. Desai SD, Emanuel AL, Sinha VK (2003) Polyester polyol-based polyurethane adhesive; effect of treatment on rubber surface. J Polym Res 10:141-149

68. Chujo Y, Tatsuda T, Yamashita Y (1982) Synthesis of polyurethane graft copolymers by polyaddition reaction of dihydroxyl-terminated macromonomers. Polym Bull 8:239-244

69. Slocombe RJ, Hardy EE, Saunders JH, Jenkins RL (1950) Phosgene derivatives for the preparation of isocyanates, carbamyl chlorides and cyanuric acid. J Am Chem Soc 72:1888-1891

70. Figovsky O, Shapovalov L, Leykin A, Birukova O, Potashnikov R (2013) Recent advances in the development of non-isocyanate polyurethanes based on cyclic carbonates. Pu Mag 10:1-9

71. Mol JC (2002) Application of olefin metathesis in oleochemistry: an example of green chemistry. Green Chem 4:5-13

72. Mgaya JE, Mubofu EB, Mgani QA, Bartlett S, Slawin AM, Pogorzelec P, Cole-Hamilton DJ (2016) Synthesis of bifunctional monomers via palladium catalyzed carbonylation of cardanol and its derivatives. Chem Cat Chem 8(4):751-757

73. da Silva EC, da Silva MGA, Meneghetti SMP, Machado G, Alencar MARC, Hickmann JM, Meneghetti MR (2008) Synthesis of colloids based on gold nanoparticles dispersed in castor oil. J Nanopart Res 10:201-208 
74. Wender H, de Oliveira LF, Feil AF, Lissner E, Migowski P, Meneghetti MR, Teixeira SR, Dupont J (2010) Synthesis of gold nanoparticles in a biocompatible fluid from sputtering deposition onto castor oil. Chem Commun 46:7019-7021

75. Zamiri R, Zakaria A, Abbastabar H, Darroudi M, Husin MS, Mahdi MA (2011) Laser-fabricated castor oil-capped silver nanoparticles. Int J Nanomed 6:565-568

76. Gherca D, Pui A, Cornei N, Cojocariu A, Nica V, Caltun O (2012) Synthesis, characterization and magnetic properties of $\mathrm{MFe}_{2} \mathrm{O}_{4}(\mathrm{M}=\mathrm{Co}, \mathrm{Mg}, \mathrm{Mn}$, $\mathrm{Ni})$ nanoparticles using ricin oil as capping agent. J Magn Magn Mater 324:3906-3911

77. Kyobe JW, Mubofu EB, Makame YMM, Mlowe S, Revaprasadu N (2015) CdSe quantum dots capped with naturally occurring biobased oils. New J Chem 39:7251-7259
78. Kyobe JW, Mubofu EB (2016) Makame YMM., Mlowe S, Revaprasadu N Cadmium sulfide quantum dots stabilized by castor oil and ricinoleic acid. Physica E 76:95-102

79. Shombe GB, Mubofu EB, Mlowe S, Revaprasadu N (2016) Synthesis and characterization of castor oil and ricinoleic acid capped CdS nanoparticles using single source precursors. Mater Sci Semicond Process 43:230-237

80. Gebru H, Taddesse A, Kaushal J, Yadav OP (2013) Green synthesis of silver nanoparticles and their antibacterial activity. J Surf Sci Technol 29:47-66

\section{Submit your manuscript to a SpringerOpen ${ }^{\circ}$ journal and benefit from:}

- Convenient online submission

- Rigorous peer review

- Immediate publication on acceptance

- Open access: articles freely available online

- High visibility within the field

- Retaining the copyright to your article 